Interactive comment on "Multi-model simulations of springtime dust storms in East Asia: Implications of an evaluation of four commonly used air quality models (CMAQv5.2.1, CAMxv6.50, CHIMEREv2017r4, and WRF-Chem v3.9.1)" by Siqi

\title{
Ma et al.
}

Siqi Ma et al.

zhangxuelei@neigae.ac.cn

Received and published: 25 August 2019

The comment was uploaded in the form of a supplement:

https://www.geosci-model-dev-discuss.net/gmd-2019-57/gmd-2019-57-AC4supplement.zip 
2019.

GMDD

Interactive

comment 